\title{
LA JERARQUÍA NORMATIVA DE LOS TRATADOS SOBRE DERECHOS HUMANOS EN LA CONSTITUCIÓN Y LA JURISPRUDENCIA DE NICARAGUA.
}

\author{
Byron G. Cárdenas Velásquez ${ }^{6 *}$ \\ Candidato a Doctor en Derecho Público \\ por la Universidad Autónoma de Barcelona \\ byrocar@hotmail.com
}

Resumen: La incorporación de los tratados internacionales sobre derechos humanos en la Constitución Política de Nicaragua (artículos 46 y 71) ha dado lugar a diversas interpretaciones sobre su posicionamiento normativo en el sistema de fuentes, precisamente por la ambigüedad de la norma en ese sentido. La más reciente jurisprudencia de la Sala Constitucional de la Corte Suprema de Justicia ha entendido que los citados tratados ostentan un rango constitucional; por contra, los instrumentos internacionales del artículo 182 que los ha ubicado a nivel infraconstitucional. No obstante, la Sala Constitucional dejó inconclusa la situación jerárquica de los tratados excluidos de la lista del artículo 46, lo cual, podría encontrar una solución en la interpretación axiológica y progresista de la norma, a partir de los criterios hermenéuticos de las normas internacionales y la jurisprudencia de la Corte Interamericana de Derechos Humanos. Es decir, adoptando criterios similares a los de las salas y cortes constitucionales de Argentina, Colombia y Costa Rica.

Abstract: The incorporation of international treaties on human rights in the Constitution of Nicaragua (Articles 46 and 71) has led to various interpretations of its legal status in the domestic law, because of the ambiguity of those Articles. The most recent jurisprudence of the Constitutional Chamber of the Supreme Court has understood that the mentioned treaties are at the same constitutional level, by contrast, the international treaties of Article 182 that are located under constitutional level. However, the Constitutional Chamber left unfinished the hierarchical status of treaties excluded from the list in Article 46, which could find a solution in the axiological and

65 Becario de la Agencia Española de Cooperación Internacional al Desarrollo (AECID). 
progressive interpretation of the norm, from the interpretive criteria of international standards and jurisprudence of the Inter-American Court of Human Rights. That is, adopting criteria similar to those of the Chambers and Constitutional Courts of Argentina, Colombia and Costa Rica.

Palabras claves: Derecho Constitucional / Derecho Internacional de los Derechos Humanos / Jurisprudencia Interamericana / Jurisprudencia Interna.

Key words: Constitutional Law / International Human Rights Law / Jurisprudence of the Inter-American Court of Human Rights / National Jurisprudence.

Tabla de Contenido: I. Introducción; II. Relación entre el Derecho Internacional y el Derecho Interno; 1. El Dualismo, 2. El Monismo, III. Los derechos humanos como vínculo sustancial entre el Derecho Internacional y el Derecho Interno; IV. La recepción del Derecho Internacional en la Constitución de Nicaragua; V. La interpretación de los tratados sobre derechos humanos en la jurisprudencia constitucional de Nicaragua; VI. Conclusiones Generales; VII. Lista de referencias.

\section{Introducción}

La compleja relación entre el Derecho Internacional y el Derecho Interno ha estado marcada por antagonismos propios de ambos sistemas normativos, del que regula las relaciones interestatales y del que regula las relaciones institucionales y de su población. Desde principios del Siglo XX la doctrina ha tratado de superar las contradicciones entre ambos bajo los postulados de las teorías "dualista" y "monista". Sin embargo, a partir del reconocimiento de la subjetividad internacional del individuo, a mitad del siglo pasado, los planteamientos clásicos de aquellas teorías fueron revisados bajo los nuevos parámetros del Derecho Internacional de los Derechos Humanos (DIDH). Así, los Estados se vieron exigidos a adecuar su orden jurídico interno a las normas internacionales sobre derechos humanos, por lo cual tuvieron que realizar ciertos ajustes constitucionales necesarios para incorporar y jerarquizar los instrumentos internacionales en el sistema de fuentes.

En ese contexto, Nicaragua, ha seguido los lineamientos marcados por la realidad jurídica contemporánea y ha integrado diversos instrumentos internacionales sobre derechos humanos (tratados, pactos, protocolos, convenciones y declaraciones) en el texto constitucional (artos. 46 y 71). No obstante, las ambigüedades e insuficiencias normativas del texto constitucional han puesto en evidencia algunos problemas de interpretación para la Sala Constitucional respecto a la jerarquía y los efectos jurídicos de los instrumentos incorporados, 
que ha discurrido a la desarticulación de ambos sistemas normativos y de los mecanismos internos de tutela de derechos.

El presente artículo, parte de aquellas cuestiones para colocar en perspectiva, en primer lugar, la relación entre el Derecho Internacional y el Derecho Interno de Nicaragua, a la luz de las disposiciones constitucionales relativas a la incorporación de los instrumentos internacionales en el ordenamiento jurídico nacional. En segundo lugar, aplicaría a conocer el aporte de la jurisprudencia de la Sala Constitucional en la determinación del valor interpretativo de los citados instrumentos en la actividad jurisdiccional de la Máxima Magistratura, así como la delimitación del rango jerárquico de las normas internacionales en el Derecho local que nos permita identificar la postura doctrinaria adoptada por Nicaragua en ese sentido. Por último, tercer lugar, se ha propuesto examinar los fundamentos teóricos y jurisprudenciales en el Derecho comparado, que permitan verificar la jerarquía constitucional de los tratados excluidos de los artículos 46 y 71 de la Constitución Política (en adelante Cn.).

\section{Relación entre el Derecho Internacional y el Derecho Interno}

Las formulaciones clásicas en las obras de Hans Triepel y Dionisio Anzilotti, sobre la relación del Derecho Internacional y el Derecho Interno, fueron el punto de partida para el tratamiento doctrinario de la relación entre ambos sistemas jurídicos bajo la teoría Dualista. No obstante, la crítica a los "dualistas" luego dio lugar a la corriente del Monismo, fundada principalmente por Hans Kelsen, Alfred Verdross, Hugo Krabbe y Georgeos Scelle, Philip y Albert Zorn (Verdross, 1974; Ruiz, 1997; Kelsen, 1979; Malpica, 2002). Así, desde principios del siglo pasado el debate teórico se centró en desentrañar las particularidades del Derecho Internacional y el Derecho Interno para encontrar sus compatibilidades o entendimiento, bien, a partir de la coordinación entre ambos, o bien, en la subordinación de uno al otro.

Si bien, los debates teóricos han dado un giro importante con la apertura del Derecho Internacional de los Derechos Humanos, en la praxis se sigue recurriendo a la nomenclatura de aquellos postulados doctrinarios para examinar la recepción del Derecho Internacional en el Derecho Interno. De forma que en la literatura es frecuente recurrir al uso del "dualismo" o "monismo" para determinar la interacción de los dos sistemas normativos en el ámbito estatal.

\section{El Dualismo}

La teoría Dualista o Pluralista, fundada por Triepel y Anzilotti, afirma que el Derecho internacional y el Derecho interno son dos ordenamientos jurídicos 
absolutamente separados, por tener fundamentos de validez y destinatarios distintos. Mientras las normas del Derecho Internacional son producidas según un procedimiento internacional y obligan tan solo a comunidades soberanas, el derecho estatal, con arreglo a esta concepción, arraiga en su constitución, la única que puede originar derechos y deberes para individuos (Verdross, 1974). De esa forma, el Derecho Internacional sólo puede aplicarse a las relaciones entre los Estados coordinados entre sí. El particular, es incapaz de ser investido de derechos y deberes propios derivados del sistema jurídico de esta comunidad, únicamente, puede ser investido en virtud de una regla de Derecho Interno enteramente ligada a una regla de Derecho Internacional (Ruiz, 1997).

En la práctica la adopción del "dualismo" es especialmente perceptible en ciertos países del Consejo de Europa, donde el Convenio Europeo de Derecho Humanos o "Convenio de Roma" ha sido transformado en Derecho Interno mediante el desarrollo legislativo interno en la Republica Federal de Alemania, Luxemburgo, Malta, Italia, San Marino, Grecia, Chipre, Finlandia y Dinamarca (Ruiz, 1997).

\section{El Monismo}

El Monismo, crítica de Kelsen al "dualismo", plantea la unidad de ambos cuerpos normativos en un sistema jurídico unitario correlativo a la unidad del conocimiento normativo. Es decir, que no admite dos o más normas u órdenes, que deban estar vigentes, situados uno al lado de otro, sin referir la validez de ambos a un único y mismo fundamento (Ruiz, 1997). Para Verdross (1974), existe un "monismo moderado o estructurado que parte de la posibilidad de conflictos entre el Derecho Internacional y el Derecho Interno", pero tales conflictos no tienen carácter definitivo y encuentran su solución en la unidad del sistema jurídico (p.65).

El "monismo" a diferencia del "dualismo" admite diversas modalidades. Una primera variante es el "monismo" de primacía del orden jurídico nacional, fundado por Philip y Albert Zorn, sostiene que el Derecho internacional sólo es válido en la medida que el Estado le haya reconocido carácter obligatorio. Una segunda variante es el "monismo" de primacía del Derecho internacional, propuesta por Hugo Krabbe y George Scelle, establece que el Derecho interno está sometido al Derecho internacional y no puede ser soberano. Una tercera variante e el "monismo" de libre elección, de primacía del Derecho interno o Derecho internacional, defendida por Kelsen, que aduce que la ciencia no conoce el método de dar preferencia a uno sobre otro por razones jurídicas, ya que se trata de supuestos de Teoría del Derecho (Ruiz, 1997; Malpica, 2002). 
El caso práctico de este modelo lo encontramos en España, los Países Bajos, Portugal, Austria, donde las constituciones de esos países integran de forma directa los tratados internacionales, es decir, de forma autónoma al desarrollo legislativo posterior (Ruiz, 1997).

\section{Los Derechos Humanos como vínculo sustancial entre el Derecho Internacional y el Derecho Interno}

Si bien, la relación entre las normas internacionales y el Derecho Interno ha sido arduamente tratada en la doctrina, es claro que ninguno de aquellos postulados se refirió al individuo como sujeto de Derecho Internacional, en virtud del ulterior surgimiento del DIDH. En ese sentido, con el desarrollo de normas internacionales con contenidos regulatorios sobre los derechos humanos, el debate teórico ha supuesto un replanteamiento de aquellas formulaciones clásicas sobre la relación entre ambos sistemas normativos, en vista de la incuestionable preeminencia de las normas internacionales relativas a la protección del ser humano. Por consiguiente, habría que empezar, por una parte, por distinguir las diferencias entre el Derecho Internacional Clásico y el DIDH con el objeto de ubicarnos en el nuevo escenario internacional, y, por otra, en establecer las interconexiones del DIDH con el Derecho Interno que nos aproximen a identificar los presupuestos de la nueva relación jurídica.

En cuanto al primer asunto, es destacable que ha sido la misma Corte Interamericana de Derechos Humanos quien ha precisado ciertos elementos distintivos entre los tratados internacionales tradicionales y los tratados sobre derechos humanos. Para tal efecto, el Tribunal regional sostuvo en la Opinión Consultiva OC-2/82 (1982) que los tratados tradicionales están en "función de un intercambio recíproco de derechos y beneficios entre los Estados contratantes", es decir, que el individuo está exento de su amplio espectro normativo, por cuanto las obligaciones adquiridas por los Estados son en función de intereses estrictamente interestatales, por ejemplo, tratados limítrofes, comerciales, militares o políticos. Por el contrario, los tratados sobre derechos humanos enmarcan su "objeto y fin en la protección de los derechos fundamentales de los seres humanos, independientemente de su nacionalidad, tanto frente a su propio Estado como frente a los otros Estados contratantes". En ese sentido, cuando un Estado decide aprobar estos tratados, "se someten al orden legal dentro del cual ellos, por el bien común asumen varias obligaciones, no en relación con otros Estados, sino hacia los individuos bajo su jurisdicción” (párr. 29).

Ciertamente, las diferencias señaladas revelan no solo un nuevo orden jurídico al que se somete los Estados, sino un nivel de compromiso y obligación distinto, por cuanto la protección del ser humano es el fin mismo de aquellas 
regulaciones internacionales que, además, van a comportar una obligación erga omnes $^{66}$. En ese sentido, es remarcable que el reconocimiento de la subjetividad internacional del individuo ha significado el desplazamiento del Estado como único sujeto de Derecho Internacional; en virtud que su protección no es más una exclusividad de éste, sino, también, de los tribunales internacionales. En consecuencia, el alcance universal de los derechos humanos, como advierte Trindade (2003), ha significado, además, la superación del "arcaico dogma positivista" que autoritariamente reducía tales derechos a los concedidos por el Estado, en razón de la clásica idea de la soberanía estatal absoluta (p.12).

El imperativo de la protección universal del ser humano, entonces, aparece como un elemento incontrovertible y ajeno a "la vieja polémica entre los "monistas" y "dualistas", la cual, según Trindade (2003), "restó esfuerzos en pro de la emancipación del individuo vis-à- vis su propio Estado" (p.13). En todo caso, la importancia de los postulados "monista" y "dualista", como señala Arguello (2001), será manifiestamente relevante para los tribunales nacionales no para los internacionales, por cuanto determinará el valor y la vinculación jurídica que las normas internacionales clásicas tendrán para los tribunales internos y órganos estatales.

Por otra parte, en el nuevo escenario internacional la relación entre el Derecho Internacional y el Derecho Interno se circunscribe a la correspondencia en aquellos aspectos que le son comunes: los derechos humanos. Para Abregú (1997), la complementariedad entre ambos sistemas legales se basa en que en el ámbito internacional los derechos humanos se sostienen en los principios generales del Derecho internacional, y en el ámbito local la aplicación interna del derecho internacional de los derechos humanos exige una retroalimentación con el Derecho constitucional. Por tanto, el impacto de un tratado de derechos humanos en el Derecho interno de un Estado pasa, necesariamente, por la adecuación de las normas de orden doméstico que se le opongan, así como el fortalecimiento de los mecanismos de tutela de derechos y los ajustes

66 Sobre este aspecto la Corte Interamericana de Derechos Humanos ha señalado que "[...] la obligación de respetar ciertos derechos humanos esenciales es considerada hoy como una obligación erga omnes (Corte Interamericana (Corte IDH) OC-10/89, Interpretación de la Declaración Americana de los Derechos y Deberes del Hombre en el Marco del Artículo 64 de la Convención Americana sobre Derechos Humanos. párr. 38). En la sentencia de fondo del caso Goiburú y otros vs. Paraguay (2006), el Tribunal interamericano sostuvo que "el acceso a la justicia constituye una norma imperativa de Derecho Internacional y, como tal, genera obligaciones erga omnes para los Estados" (párr. 131). En ese mismo sentido, en el voto razonado de Cançado Trindade (2006) de la citada sentencia, consideró que "no puede haber duda de que las garantías fundamentales, comunes al Derecho Internacional de los Derechos Humanos y al Derecho Internacional Humanitario, tienen una vocación universal al aplicarse en todas y cualesquiera circunstancias, y conforman un derecho imperativo (perteneciendo al jus cogens), y acarrean obligaciones erga omnes de protección” (párr. $65)$. 
constitucionales que merezca para ejecutar las decisiones de los órganos internacionales.

Así, de acuerdo con Landa (2007) frente a los inconvenientes dogmáticos y prácticos derivados de la tesis "monista" y "dualista", la posición constitucional de los tratados ha encontrado a través de "la tesis de la coordinación" una opción para la integración entre el Derecho Internacional y el Derecho Interno, sobre la base de la responsabilidad internacional; fundado básicamente "en un neoiusnaturalismo integrador" (pp.155-160). Esto es así, porque la positivización de los derechos humanos ha traído consecuencias jurídicas innegables para la dogmática constitucional; por una parte, por los efectos jurídicos y carácter selfexcuting de los tratados constitucionalizados y, por otra parte, por la significación de su posicionamiento frente a las demás leyes.

\section{La recepción del Derecho Internacional en la Constitución Política de Nicaragua}

La referencia al Derecho Internacional en el orden interno la vamos encontrar en la Constitución Política de Nicaragua y demás leyes, bajo las expresiones "tratados" e "instrumentos internacionales" ${ }^{67}$, en clara alusión a la diversidad de normas que integran el Derecho Internacional (tratados, convenciones, declaraciones, pactos, protocolos, etc.); aunque, la terminología genérica tampoco distingue de las normas vinculantes y las declarativas. Concretamente, los artículos 46 y 71 in fine Cn consagra la apertura del constitucionalismo latinoamericano hacia la integración del DIDH en el Derecho Interno. El primero, mediante una cláusula declarativa que reconoce la "plena vigencia de los derechos inherente a la persona” consignados en la Declaración Universal de Derechos Humanos, la Declaración Americana de Derechos y Deberes del Hombre, el Pacto internacional de Derechos Económicos, Sociales y Culturales, el Pacto Internacional de Derechos Civiles y Políticos y la Convención Americana de Derechos Humanos". Y el segundo, también, declarando la "plena vigencia" de la Convención de los Derechos del Niño. No obstante, haciendo notar ciertas imprecisiones jurídicas, entre otras, respecto a la jerarquía de los tratados internacionales incorporados en el sistema de fuentes, los efectos jurídicos directos o su exigibilidad jurídica ante los tribunales de justicia. Así como los criterios de los tratados internacionales para la interpretación de los derechos reconocidos a nivel constitucional.

67 Por ejemplo, los artículos 5 in fine, 138.12 y 150.8, 182 de la Constitución Política (Cn), el artículo 5 de la Ley de Amparo (Ley No 49), el artículo 4 de la Ley Orgánica del Poder Judicial (Ley 260), y el artículo 124 de la Ley Orgánica del Poder Legislativo (Ley No 606). 
En cuanto a los efectos jurídicos de los instrumentos internacionales, habría que remitirse a los aspectos formales relativos a la incorporación de los citados tratados en el Derecho interno, contenidos en la Constitución y leyes secundarias, para examinar con mayor detenimiento las regulaciones en ese sentido. Los artículos 138.12 y 150.8 Cn señalan que la Asamblea Nacional tiene la atribución para "aprobar o rechazar los instrumentos internacionales celebrados con países u organismos sujetos de Derecho Internacional”, sin embargo, el texto constitucional no establece el procedimiento a seguir para la aprobación de los tratados, para ello hay que remitirse a la Ley Orgánica del Poder Legislativo (Ley $\mathrm{N}^{0}$ 606). El artículo 124 de la Ley $\mathrm{N}^{0}$ 606, establece que la aprobación de los instrumentos internacionales se realizará mediante Decretos Legislativos, que luego serán publicados en la Gaceta, Diario Oficial. El último párrafo del mismo artículo señala que "La aprobación legislativa le conferirá efectos legales dentro y fuera de Nicaragua, una vez que haya entrado en vigencia internacionalmente, mediante deposito o intercambio de ratificaciones o cumplimiento de los requisitos o plazos, previsto en el texto del instrumento internacional”.

$\mathrm{Al}$ tenor de aquellas disposiciones, los instrumentos internacionales que han superado el trámite de aprobación y han sido incorporados en el Derecho local adquieren efectos legales inmediatos desde su publicación, salvo disposiciones contenidas en el propio instrumento, en igual medida a los efectos jurídicos que produce una ley emanada de la instancia legislativa. Se trata, entonces, de una incorporación directa que le posiciona bajo el modelo "monista", si partimos que no requerirá de un desarrollo legislativo posterior para su operatividad, aunque, no queda claro si será un "monismo" de primacía del Derecho Interno o del Derecho Internacional. En todo caso, las regulaciones sobre la aprobación de tales instrumentos no causa ningún efecto sobre la jerarquía que éstos van a tener en el Derecho interno, pues aquella será una cuestión a resolver por la misma Constitución Política, como veremos adelante.

La recepción de las normas internacionales en general, no obstante, acusa exiguo acierto normativo, por cuanto las previsiones de la Constitución y la Ley 606 no contemplan la incorporación de instrumentos internacionales con disposiciones contrarias a la Constitución, como, por ejemplo, sí es regulado en las constituciones de Honduras (arto. 17) y de Perú (arto. 57), donde es seguido bajo el procedimiento previsto para la reforma parcial a la Constitución ${ }^{68}$. Esto es así, porque, si bien, la supremacía constitucional se ejerce sobre los tratados internacionales (arto. 182), las presupuestos legales para el Control

68 De acuerdo con Ayala (1998) aquellas previsiones legales en Honduras y Perú ponen de manifiesto la tesis de la supraconstitucionalidad de los tratados internacionales, por vía de la reforma parcial constitucional. 
de Constitucionalidad ${ }^{69}$ no contemplan ni el Control previo ni el Control $a$ posteriori de constitucionalidad de los tratados ${ }^{70}$. Por tanto, el contenido difuso de las regulaciones generales (Ley $\mathrm{N}^{\circ} 606$ ), tampoco logra articular las normas internacionales de forma coherente con el Derecho Interno.

Ahora bien, en cuanto a la jerarquía de los instrumentos internacionales en el Derecho interno, como se ha señalado, es un asunto a ser determinado por la propia Constitución. De ese modo, la posición "monista" o "dualista" que el Estado adopte sólo puede ser estipulada por el texto constitucional (Ayala, 1998), así, los instrumentos internacionales no pueden ostentar un estatus jurídico per se desde su entrada en vigor en el Derecho local. Por tanto, la jerarquización de los tratados, pactos, protocolos convenciones y declaraciones la vamos encontrar bajo cláusulas constitucionales que le van reconocer un estatus "supraconstitucional", "constitucional", "infraconstitucional o legal" (Sánchez, 1994; Dulitzky, 1997; Trindade, 1998) 71 $^{71}$

La referencia más cercana de la Constitución nicaragüense, sobre el rango normativo de los tratados internacionales, la vamos encontrar en la cláusula de supremacía constitucional del artículo 182, la cual estipula que "No tendrán valor alguno las leyes, tratados, decretos, reglamentos, órdenes o disposiciones que se le opongan o alteren sus disposiciones”. De la literalidad del artículo se desprende que los tratados internacionales en general adquieren un rango infraconstitucional, pues en caso de entrar en conflicto con la Constitución primaría ésta en virtud de su supremacía normativa. La jerarquía de los instrumentos internacionales, examinada así, no implicaría ninguna controversia de no ser por la inclusión en el texto constitucional de la lista de tratados del artículo 46, que pone en entredicho la tesis de la infraconstitucionalidad de los tratados internacionales señalada. En ese sentido, como ha sostenido Manili (2002), habría que remontarse a la intención del Constituyente para comprender que quiso decir con la prescripción del artículo 46, pues en sentido estricto podría significar la aplicabilidad directa y la operatividad inmediata de las normas contenidas en aquellos tratados incorporados, o bien, implicaría una

69 Capítulo II, Título X de Cn.

70 Como, por ejemplo, si es regulado en de Constitución española de 1978 (arto. 95) que establece que la celebración de un tratado internacional que contenga estipulaciones contrarias a la Constitución exigirá la previa revisión constitucional. El gobierno o cualquiera de las cámaras puede recurrir al Tribunal Constitucional para que declare si existe o no esa contradicción. La declaración que emita dicho Tribunal tendrá carácter vinculante (arto. 78.3 de la Ley Orgánica del Tribunal Constitucional).

71 Por ejemplo, el artículo 15, 16 y 18 de la Constitución de Honduras, el artículo 93 de la Constitución de Colombia, el artículo 7 de la Constitución de Costa Rica, el artículo 46 de la Constitución guatemalteca, el artículo 3, 105 y Disposición Final y Transitoria Cuarta de la Constitución del Perú, el artículo 23 de la Constitución de Venezuela y el artículo 75.22 de la Constitución argentina. 
excepción al artículo 182 constitucional, de manera que se pueda sostener la jerarquía constitucional de los tratados enumerados.

La verificación del estatus constitucional de los instrumentos incorporados en el artículo 46, y como excepción del artículo 182, es particularmente válida si es concebida en el contexto de un tratamiento especial y diferenciado, aunque implícito, de los instrumentos internacionales sobre derechos humanos frente a otros tratados internacionales de diferente materia en el texto constitucional. Es decir, que el Constituyente haya querido privilegiar y posicionar de forma preferente a las normas internacionales que contienen regulaciones sobre la protección del ser humano frente aquellas referidas a asuntos exclusivamente interestatales, optando por la incorporación de una serie de instrumentos de DIDH en la misma Constitución. Si tomamos en cuenta los criterios jurisprudenciales más reciente de la Corte Suprema de Justicia encontraremos que el máximo tribunal se ha posicionado, por una parte, declarando la infraconstitucionalidad de un tratado internacional en razón de la supremacía constitucional del artículo $182^{72}$; y, por otra parte, también, reconociendo el rango constitucional de los instrumentos internacionales de los artículos 46 y 71 $\mathrm{Cn}^{73}$. De esa forma, la Máxima Magistratura ha comprendido que la referencia de la Constitución a los instrumentos internacionales en los artículos 46 y 71 y 182 Cn es distinta. En los primeros se refiere a instrumentos de rango constitucional y en el segundo a instrumentos de rango inferior, al menos, infraconstitucional, pues tampoco se precisa si se ubicarían en un rango intermedio entre la norma fundamental y las leyes ordinarias, o bien, al mismo nivel jerárquico de éstas.

No obstante, la cláusula enunciativa del artículo 46, como sostiene Ayala (1998), representa un problema de desactualización frente a nuevos instrumentos que puede originar dificultades interpretativas. En ese sentido, dicho precepto entraña otra cuestión constitucional a resolver; esto es, conocer cuál es la jerarquía normativa de los instrumentos sobre derechos humanos excluidos del texto constitucional ${ }^{74}$, lo cual, de acuerdo con Ayala (1998) podría encontrar

72 Así, con la Sentencia No 15 de las doce meridiana del 29 de marzo de 2005, el Pleno de la Corte Suprema de Justicia declaró la inconstitucionalidad en el caso concreto del artículo 22.f. del Estatuto de la Corte Centroamericana de Justicia, por ser contrario al artículo 164.12 de la Constitución, de conformidad a la cláusula de supremacía constitucional de los artículos 182 constitucional y 5 de la Ley de Amparo.

73 Sala Constitucional. Sentencia No. 57/2010, del día dos de marzo del año dos mil diez, a las doce y treinta minutos de la tarde.

74 Por ejemplo, la Convención Internacional sobre la Eliminación de todas las Formas de Discriminación Racial, Protocolo adicional a la Convención Americana "Pacto de San Salvador" sobre Derechos Económicos, Sociales y Culturales, la Convención sobre la eliminación de todas las formas de discriminación contra la mujer (CEDAW), la Convención contra la Tortura y Otros Tratos o Penas Crueles, Inhumanos y Degradantes, la Convención internacional sobre la protección de los derechos de todos los trabajadores migratorios y de sus familiares, la Convención Interamericana 
solución en la interpretación de la "proyección progresiva de la norma", considerando que la enumeración de los instrumentos es a "título enunciativo y no taxativo, que deberá entenderse como numerus apertus no excluyente" (p.51). Asimismo, la declaración en términos generales del reconocimiento de "derechos inherentes a las personas" del artículo 46 implicaría una referencia a otros derechos excluidos del texto constitucional; es decir, también, un reconocimiento implícito de derechos, haciendo constar su equivalencia con los derechos constitucionalizados.

Desde esa perspectiva, los derechos internacionales integrados en el orden jurídico interno van a adquirir un rango constitucional no autónomo, sino en virtud de aquel reconocimiento implícito de derechos en la Constitución, porque los derechos recogidos en el texto se configuran en un sistema abierto a los derechos contenidos en los instrumentos internacionales. Se puede inferir, como ha sostenido Bazán (2006) para el caso Argentino, que existen instrumentos internacionales sobre derechos humanos que ostentan una "jerarquía constitucional originaria y otros que recepciona una jerarquía constitucional derivada"(p. 374). Los primeros, serían aquellos instrumentos enunciados en los artículos 46 y 71 y los segundos los instrumentos internacionales sobre derechos humanos aprobados y ratificados por Nicaragua, y excluidos del texto constitucional.

De cualquier modo, como advierte Zalgrebelsky (2007), hay que comprender que la Constitución en el tema de la dignidad e igualdad de todos los seres humanos y de los derechos fundamentales aspira a la universalidad, y que su interpretación no es la de "un contrato, de una decisión administrativa, y ni siquiera de una ley emanada de voluntades políticas contingentes" (p.94). Por tanto, los criterios de interpretación de la norma fundamental discurre hacia la consolidación de perspectivas universales, por cuanto los derechos humanos reconocidos a nivel constitucional e internacional se comprenden correlativamente a partir de ese conjunto de principios y valores, pues la rigidez de las constituciones no puede entenderse al margen de "los vínculos de contenido como los principios y derechos fundamentales" (Ferrajoli, 2007, p.76).

sobre Concesión de los Derechos Políticos de la Mujer, la Convención Interamericana sobre Restitución Internacional de Menores, el Protocolo a la Convención Americana sobre Derechos Humanos relativos a la Abolición de la Pena de Muerte, la Convención interamericana para prevenir, sancionar y erradicar la violencia contra de la mujer, la Convención Interamericana para la Eliminación de todas las formas de discriminación contra las personas con discapacidad, el Convenio 169 de la OIT sobre "Pueblos Indígenas y Tribales en pueblos independientes" y la Convención Interamericana para prevenir y sancionar la tortura. 
Por ultimo, habría que decir que por imperativo del principio pacta sunt servand ${ }^{75}$, la obligación internacional de Nicaragua respecto a la lista de instrumentos incorporados en el texto constitucional es igual para aquellos excluidos del mismo. Y tratándose de instrumentos que reconocen básicamente los mismos derechos y libertades, como ha sostenido Ridruejo (2008), el conflicto es muy poco probable, además, porque las instancias nacionales están obligadas a interpretar los derechos fundamentales de acuerdo a los instrumentos internacionales, reduciendo así la posibilidad de conflicto. En todo caso, en el supuesto de antinomia entre una norma de un tratado sobre derechos humanos y la Constitución, prevalecerá aquella que ofrezca una mayor protección para la persona en virtud del principio internacional pro homine, también, incorporado en el artículo 5 constitucional.

\section{La interpretación de los tratados sobre derechos humanos en la jurisprudencia constitucional de Nicaragua}

La compleja relación entre el Derecho Internacional y el Derecho Interno nicaragüense ha estado marcada por un exiguo acierto normativo de la propia Constitución, sin embargo, tales desaciertos no han encontrado en la jurisprudencia de la Sala Constitucional de la Corte Suprema de Justicia los criterios de interpretación para articular ambos sistemas de normas coherentemente, por el contrario ha recepcionado un tratamiento dispar en la jurisprudencia interna. Es así, que en las sentencias precedentes al fallo $\mathrm{N}^{\circ} 57 \mathrm{de}$ 2010, la Sala se restringió a la literalidad del artículo 46 para reconocer "la plena vigencia" de los instrumentos recogidos allí ${ }^{76}$. La imperceptible trascendencia de aquellos criterios jurisprudenciales postergó ciertos asuntos concernientes a aclarar las imprecisiones del texto constitucional sobre la jerarquía de los instrumentos internacionales en el sistema de fuentes, su valor interpretativo, o bien, su carácter operativo o programático de las normas internacionales incorporadas en el orden interno.

Con la sentencia 57/2010y, más tarde, con el fallo 78/2010, la Sala Constitucional logró superar el dilema, si cabía, sobre el estatus constitucional de los tratados internacionales del 46 y 71 en el orden interno. Para tal efecto sostuvo:

75 Consagrado en el artículo 26 de la Convención de Viena sobre Derechos de los Tratados y reconocido en el artículo 5 de la Constitución Política.

76 Cfr. Sala Constitucional de la Corte Suprema de Justicia de Nicaragua. Sentencia No 13 de 1997; Sentencia $N^{\circ} 160$ de 12 de septiembre de 2000; Sentencia $N^{\circ} 49$ de 31 de enero de 2001; Sentencia $\mathrm{N}^{\mathrm{o}} 13$ del 5 de febrero de 2002; Sentencia 115 del 2 de junio de 2003; Sentencia No 59 del 7 de mayo de 2004; Sentencia No 10126 de agosto de 2004; Sentencia No 136 de 4 de noviembre de 2004; Sentencia No 46 de 21 de diciembre de 2004. 
“[...]las disposiciones de los artículos 46 y párrafo segundo del 71, otorga a estos instrumentos internacionales rango y reconocimiento constitucional, los integra con carácter de normas constitucionales, por tanto, en el ámbito de la jerarquía normativa comparten el carácter de Supremacía que la Constitución Política tiene frente a las normas ordinarias del ordenamiento jurídico"77.

De esa forma, los citados fallos marcaron un punto de inflexión respecto al reconocimiento del estatus constitucional de aquellos instrumentos internacionales sobre derechos humanos. Empero, el ajustado examen de las disposiciones constitucionales se circunscribió a la verificación del rango normativo de los instrumentos incorporados en la norma fundamental, dejando inconclusa la situación jerárquica de los tratados sobre derechos humanos no mencionados en los citados artículos. La nueva cuestión constitucional, ya sobrevenida $^{78}$, plantea para la Máxima Magistratura el desafío de ampliar los criterios de interpretación de las disposiciones constitucionales relativas a la incorporación del DIDH, que permita examinar el rango normativo de los instrumentos excluidos. Por tanto, el análisis jurídico intuye considerar tanto los aspectos formales como los materiales de las normas constitucionales, que nos aproxime a una posición concordante o disidente de la tesis de la constitucionalidad derivada antes aludida. En todo caso, es válido considerar ciertos aspectos que podrían contribuir a allanar el camino a la comprensión integral de los derechos humanos de forma que superen aquellas cuestiones esencialmente formales, sobre la incorporación de las normas internacionales en el orden interno nicaragüense, y avance en el estudio de los vínculos materiales o sustanciales entre ambos sistemas legales.

En primer lugar, habría que reflexionar en cuál es perspectiva del alcance de los derechos humanos en el orden interno: universales o particulares. Pues, de la respuesta dependerá, como ha sostenido Zalgrebelsky (2007), el desarrollo de perspectivas jurídicas tendencialmente universales o no en esta materia. Ciertamente, como se ha dicho, la aspiración de la Constitución en cuanto al reconocimiento y protección de los derechos humanos es la universalidad, y ello es constatable en algunas connotaciones iusnaturalistas incorporadas en

77 Sala Constitucional de la Corte Suprema de Justicia de Nicaragua. Sentencia No. 57/2010, del día dos de marzo del año dos mil diez, a las doce y treinta minutos de la tarde, considerando 3; Sentencia No. 78/2010, del día diez de marzo del año dos mil diez, a las cuatro y diez minutos de la tarde, considerando 3 .

78 Cabe recordar el exhorto del Comité para el Eliminación de la Discriminación Racial de la ONU a Nicaragua para que encontrara la "posibilidad de incluir la Convención [Internacional contra la Discriminación Racial] en la lista de tratados internacionales que figuran en el artículo 46 de la Constitución”, en razón del estatus ordinario de la Convención. Véase las Observaciones Finales del Comité para la Eliminación de la Discriminación Racial (CERD/C/NIC/CO/14). 
el texto cuando se refiere a los derechos como "inherentes a la persona" y al "respeto a la dignidad humana"79. Tal consideración nos aproximaría a una noción de derechos anteriores al mismo Estado, o de otra forma, de positivación de derechos de alcance universal ${ }^{80}$. Sin duda alguna, las implicaciones jurídicas de aquellas expresiones no tienen un valor estrictamente académico, sino, por el contrario, de gran relevancia para la actividad jurisdiccional interna, por lo cual, el reto del máximo interprete de la norma constitucional será desentrañar su contenido y su efecto irradiador en el Derecho Interno.

En segundo lugar, asumiendo el contexto de los derechos, el plexo de los derechos no se puede entender al margen del corpus iuris internacional, por lo cual, de acuerdo con Bidart (1998), para interpretarlos se tiene que apelar al "conjunto de valores, de principios, de fines, y de razones históricas que alimentan a la Constitución y los tratados" (p.98). Es decir, el interprete tendrá que prestar especial atención a los principios fundamentales reconocidos en el artículo 5 Cn -la libertad, la justicia y el respeto a la dignidad humana-, como de todos los principios internacionales a los que se adhiere Nicaragua, en virtud que los principios constitucionales, según Rodríguez-Torubes (2000), imponen un mínimo de respeto para "la realización de la mayor medida posible delos valores", y porque representan los "instrumentos imprescindibles para interpretar el resto de normas jurídicas y establecer o aclarar sus interconexiones"(p.34). Por tanto, la interpretación de la Norma Fundamental comportaría una perspectiva axiológica, pero, también, progresiva o evolutiva, por cuanto percibiría los derechos de forma integral e "integrados coherentemente con el derecho interno" (Meléndez, 2006).

Por último, en cuarto lugar, el carácter universal de los derechos produce un perceptible efecto de convergencia del Derecho Internacional y el Derecho Interno, y del mismo modo de una intercepción o comunicación entre las jurisdicciones internas e internacionales, que nos ubica en un escenario de "jurisdicciones concurrentes y compartidas", o si se prefiere, de "integración de jurisprudencias" (Bazán, 2007; Zalgrebelsky, 2007). Las interconexiones entre ambos sistemas legales vienen dado, como se ha señalado anteriormente, en virtud que los derechos constitucionales están conformados como un sistema abierto a la influencia de las normas internacionales que los regulan, de modo que éstas últimas sirven de criterios de interpretación de los primeros; esencialmente, por los vínculos materiales entre ambos. De esa forma, la

$79 \quad$ Así, los artículos 5 in fine y $46 \mathrm{Cn}$.

80 De acuerdo con Gavara (2004), la idea de derechos humanos se basa en la universalidad e incondicionabilidad de la pretensión de su validez. Parten de la idea de un único tipo de persona que debe ser tratada de igual modo sin diferencias de raza o cultura. Los derechos humanos son derechos de todas las personas con independencia de su nacionalidad, de forma que son reconocidos como estándar mínimo, no teniendo límites ni naturales, ni estatales. 
universalidad de los derechos aparece como un elemento controversial a la idea de impermeabilidad de la jurisprudencia nacional, argumentada, según Zalgrebelsky (2007) desde la "legitimidad de la justicia constitucional" ${ }_{1}$, precisamente, porque la protección del ser humano no es más una exclusividad del Estado, sino del Derecho internacional, donde es admitida como una obligación genérica. Ciertamente, como ha sostenido Bidart (1998), el axioma de la protección de los derechos humanos ha entrado a formar parte de los principios generales del Derecho internacional y lo ha hecho como norma imperativa e inderogable, que la jurisprudencia interamericana ha reconocido como un obligación erga omnes (supra nota 1). Por tanto, es incontrovertible que los operadores de justicia puedan emplear los criterios interpretativos de la jurisprudencia interamericana para comprender el plexo de derechos reconocidos a nivel constitucional, por cuanto es ésta la que establece el alcance y contenido de los derechos internacionalmente reconocidos. Por el contrario, lo que no pueden hacer los tribunales internos es realizar interpretaciones autónomas de los derechos contenidos en los tratados, por la evidente falta de competencia y jurisdicción, pero sí podrían declarar violaciones a derechos internacionales integrados el ordenamiento interno, por cuanto los tratados formarían parte del bloque de constitucionalidad.

Ahora bien, es indefectible que los limitados criterios hermenéuticos de la Sala Constitucional de Nicaragua impiden apreciar los derechos humanos en aquel sentido. Sin embargo, como veremos a continuación, el desarrollo de aquellas cuestiones en la jurisprudencia de algunos países de América Latina, principalmente, de Argentina, Colombia y Costa Rica, constatan la aplicación de los nuevos parámetros interpretativos de los derechos, basados en las normas y jurisprudencia internacional, para resolver no sólo el tema clásico de la jerarquía de los instrumentos internacionales en el orden interno, sino, el carácter selfexecuting u operativo de las normas internacionales incorporadas. Es evidente, como afirma Carbonell (2007), que en los cambios experimentados en la práctica jurisprudencial los intérpretes han tenido que aprender a aplicar la técnica interpretativa de los principios, la ponderación, la razonabilidad, la proporcionalidad, el efecto irradiación, la maximización de los efectos normativos de los derechos humanos, e incluso la proyección horizontal de los derechos (Drittwirkung) y el principio pro personae (pp.9-12).

Así, por ejemplo, en Argentina la Corte Suprema de la Nación se enfrentó, por primera vez, al debate sobre el valor operativo de la Convención Americana sobre Derechos Humanos en su Derecho interno en el conocido caso Ekmekdijian

81 De acuerdo con el autor "legitimidad de la justicia constitucional" implicaría la interpretación exclusiva de la Constitución, a partir de criterios eminentemente nacionales, y basada en la incomunicabilidad entre jurisprudencias internacionales y extranjeras. 
c/ Sofovich ${ }^{82}$; en el cual, dicho tribunal, recurrió a la Opinión Consultiva OC7/86 de la Corte Interamericana para decidir que en virtud de las obligaciones internacionales asumidas por Argentina le obligaba a fallar "que el artículo 14.1 [de la Convención Americana] es directamente exigible según el derecho argentino". Bajo similares criterios, en el caso Giroldi $H$. s/ recurso de casación, la Corte argentina sostuvo que estaba en la obligación de aplicar las disposiciones convencionales “...en la medida que el Estado Argentino reconoce la competencia de la Corte interamericana para conocer en todos los casos relativos a la interpretación y la aplicación de la Convención Americana"83.

En Colombia, por su parte, con la sentencia C-574 de 1992 la Corte Constitucional estableció el valor interpretativo de los principios constitucionales de carácter universal, en cuanto a la protección del núcleo común de derechos y el ejercicio del control de constitucionalidad se refiere, estableciendo que:

"Los valores y principios incluidos en el texto constitucional cumplen la función de asegurar la permanencia y obligatoriedad del contenido material de la Constitución. Aquí se refleja la voluntad constituyente de hacer obligatorio el respeto de principios considerados como universales e inherentes a la persona, cuya obligatoriedad va más allá de las contingencias propias del ordenamiento jurídico nacional”.

"La referencia a valores y principios constitucionales y supraconstitucionales, se explica como una pretensión enérgica de los constituyentes acerca de la validez material de la Constitución que implica un orden de valores que ha sido considerado por la Constitución como anterior a ella misma" ${ }^{4}$.

La Corte Constitucional de Colombia, asimismo, ha reconocido que en la medida en que la Constitución señala en el artículo 93 que los derechos y deberes deben interpretarse de conformidad con los tratados internacionales sobre derechos humanos, ratificados por Colombia, "[...]es indudable que la jurisprudencia de las instancias internacionales, encargadas de interpretar esos tratados,

82 Corte Suprema de Justicia de la Nación de Argentina. Ekmekdijian, Miguel Angel c/ Sofovich, Gerardo y otros, Exp. No. E.64. XXIII, Sentencia del 7 de julio de 1992.

83 Corte Suprema de Justicia de la Nación de Argentina. Giroldi Horacio David y Otro s/ recurso de casación, Exp. G. 342. XXVI, Sentencia del 7 de abril de 1995, fundamento 11.

84 Corte Constitucional de Colombia. Sentencia C-574 de 1992, conclusiones 2 y 6. De igual forma, en la sentencia C-225 de 1995, la misma Corte precisó que "[...]el bloque de constitucionalidad está compuesto por aquellas normas y principios que, sin aparecer formalmente en el articulado del texto constitucional, son utilizados como parámetros del control de constitucionalidad de las leyes, por cuanto han sido normativamente integrados a la Constitución, por diversas vías y por mandato de la propia Constitución". 
constituye un criterio hermenéutico relevante para establecer el sentido de las normas constitucionales sobre derechos fundamentales" ${ }^{85}$.

En ese mismo sentido, la jurisprudencia de la Sala de lo Constitucional de Costa Rica se ha nutrido de elementos internacionales para comprender el alcance y contenido esencial de los derechos constitucionalizados. La Sala ha establecido que los tratados de derechos humanos vigentes no solamente comportan un rango similar a la Constitución Política y un valor interpretativo, "[...] en la medida en que otorguen mayores derechos o garantías a las personas, priman por sobre la Constitución"86. En la sentencia 3435-92 y su aclaración, $\mathrm{N}^{\circ} 5759-93$, la Sala amplió los criterios respecto a la operatividad de las normas internacionales sobre derechos humanos, al confiarle igual valor a las normas consuetudinarias derivadas de la Declaración Americana y la Declaración Universal sobre Derechos Humanos. Empero, en la sentencia 2006-016446 fue más allá y señaló que la referencia que la Constitución hace de los "instrumentos internacionales", no significa solamente las convenciones, tratados o acuerdos, formalmente suscritos y aprobados conforme al trámite constitucional mismo, "sino cualquier otro instrumento de tenga la naturaleza propia de la protección de los Derechos Humanos, aunque no hay sufrido ese trámite, tiene vigencia y es aplicable en el país" ${ }^{87}$.

Los tribunales internos, incluso, han hecho valer los efectos vinculantes de las decisiones de la Comisión y Corte Interamericana para revocar decisiones judiciales o declarar la inconstitucionalidad de una disposición legal interna. Por ejemplo, en el caso Bramajo Hernán Javier s/ incidente de excarcelación, la Corte Suprema de Argentina revocó una resolución impugnada, al considerar que "la interpretación efectuada por el a quo del art.1 ley 24.390 [había] sido incompatible con la jurisprudencia elaborada por la Comisión interamericana de Derechos Humanos"88. Del mismo modo, en el caso Nápoli Ericka E. y otros s/ excarcelación, la misma Corte argentina recurrió a la jurisprudencia de la Corte Interamericana sobre prisión preventiva para declarar la inconstitucionalidad del artículo 12 de la ley $24.410^{89}$. Por su parte, la Sala de lo Constitucional de

85 Corte Constitucional de Colombia. Sentencia C-010 de 2000, fundamento 7. También en: Sentencias C-406/96, C-251/97, T-568/99, T-1319/01 y T-558/2003.

86 Sala de lo Constitucional de la Corte Suprema de Justicia de Costa Rica. Sentencia 3435-92, del 11 de noviembre de 1992 y su aclaración, $N^{\circ}$ 5759-93. Estos argumentos luego serían reiterados en las sentencias $5759-93$ y 2313-95 de las 16:18 hrs. de 9 de mayo de 1995 de la misma Sala.

87 Sala Constitucional de la Corte Suprema de Justicia de Costa Rica. Sentencia 2006-016446, del 15 de noviembre de 2006.

88 Corte Suprema de Justicia de la Nación de Argentina. Bramajo Hernán Javier s/ incidente de excarcelación, Exp. B. 851. XXXI, Sentencia del 12 de septiembre de 1996, fundamento 15.

89 La Corte Suprema Argentina sostuvo que "[...] la Corte Interamericana de Derechos Humanos -cuya jurisprudencia debe servir de guía para la interpretación del Pacto de San José de Costa Rica (Fallos: 318:514, considerando 11, segundo párrafo)- ha expresado que la prisión preventiva es una 
Costa Rica reconoció la validez jurídica a los criterios de la Corte Interamericana y recurrió a su Opinión Consultiva (OC-5-85 "La Colegiación Obligatoria de Periodistas") para declarar la inaplicabilidad del artículo 22 de la Ley $\mathrm{N}^{\circ} 4420$, de 22 setiembre de 1969, por ser "ilegítimo y atentar contra el derecho a la información, en el amplio sentido que lo desarrolla el artículo 13 del Pacto de San José de Costa Rica, tanto como de los artículos 28 y 29 de la Constitución Política"9o . Bajo similares criterios, en la citada sentencia 3435-92 la referida Sala de lo Constitucional, también, declaró la inaplicabilidad del artículo constitucional 14.5 por "carece de vigencia frente a los principios fundamentales que establece la Constitución Política y los Convenios Internacionales”, y en aras de evitar desigualdades y discriminaciones legal futura en razón del género dispuso el cambio en el usos de los términos "hombre" o "mujer" por el vocablo "persona” en todas la legislación aplicable ${ }^{91}$.

\section{Conclusiones Generales}

Como hemos visto, en el ordenamiento jurídico de Nicaragua no se especifica la jerarquía normativa de los instrumentos internacionales, mucho menos hace una distinción de las normas internacionales incorporadas. Sin embargo, es posible distinguir dos grupos de tratados a partir de la más reciente jurisprudencia constitucional: los de los artículos 46 y 71 y los del artículo 182. Los primeros serían aquellos relativos a la protección del ser humano y los segundos los que regulan las relaciones interestatales o asuntos propios del Derecho Internacional Clásico. En cuanto a los instrumentos del 46 y 71 , la jurisprudencia constitucional les ha reconocido con rango constitucional, en virtud de su incorporación en la Norma Fundamental, no obstante, sin hacer mención de la situación jerárquica de los tratados excluidos del texto constitucional. Por lo cual, en la actualidad aquella cuestión constitucional sigue inconclusa e indefectiblemente difusa para los sistemas internos de tutela de derechos.

medida cautelar, no punitiva, y que a su vez no debe constituir la regla general, como expresamente lo consagra el Pacto Internacional de Derechos Civiles y Políticos (art. 9.3), pues de lo contrario se estaría privando de la libertad a personas cuya responsabilidad criminal no ha sido establecida, en violación del principio de inocencia (8.2 del Pacto de San José de Costa Rica y 9.1 del Pacto Internacional de Derechos Civiles y Políticos) (conf. caso Suárez Rosero, sentencia del 12 de noviembre de 1997, párrafo 77)... Por ello y oído el señor Procurador General, se declara procedente el recurso extraordinario, se declara la inconstitucionalidad del art. 12 de la ley 24.410 y se revoca la sentencia apelada". Corte Suprema de Justicia de la Nación de Argentina. Nápoli Ericka E. y otros s/ excarcelación, Exp. N. 284. XXXII, Sentencia del 22 de diciembre de 1998, fundamentos 8 y 15. mayo de 1995, Expediente: 90-000421-0007-CO.

91 Sala Constitucional de la Corte Suprema de Justicia de Costa Rica. Sentencia 3435-92, del 11 de noviembre de 1992, Considerando I. 
Si bien, con la sentencia 57/2010 la Sala de lo Constitucional ha dado un primer paso en la jerarquización del los instrumentos internacionales al mismo nivel constitucional, no obstante, aún enfrenta retos importantes para superar la referencia eminentemente técnica-formal de los tratados en la interpretación de los derechos y aplicar el conjunto de principios y valores universales a partir de los vínculos materiales del dogmatismo constitucional y los tratados sobre derechos humanos. En ese sentido, la actividad jurisdiccional de la Sala Constitucional tendrá que avanzar en el establecimiento de criterios de interpretación uniformes del plexo de derechos reconocidos en la Constitución, a partir de la inclusión de parámetros internacionales y la jurisprudencia internacional en la materia.

Por último, habría que decir que el avance jurisprudencial experimentado por las salas y cortes constitucionales de Argentina, Colombia y Costa Rica constituye un buen ejemplo para nutrir la experiencia nicaragüense en este tema. De forma que contribuya a trascender la perspectiva positivista en la interpretación de los derechos humanos, y de un paso adelante hacia el desarrollo de criterios jurídicos universales a partir de elementos de interpretación contenido en los instrumentos internacionales y la jurisprudencia interamericana. En todo caso, el elemento innovador del DIDH y la jurisprudencia internacional no supone la afirmación de un derecho supraconstitucional, tampoco se trata, retomando a Zalgrebelsky, "de un caballo de Troya" para afirmar la dictadura universal de los derechos, sino de un instrumento para entender nuestras propias constituciones nacionales.

\section{Lista de referencias}

Abregú, M. (1997). La aplicación de los tratados sobre derechos humanos por los tribunales locales: una introducción. En M. Abregú, \& C. Courtis. (Comps.). La aplicación de los tratados sobre derechos humanos por los tribunales locales. (pp.3-31) Buenos Aires: CELS.

Ayala Corao, C. M. (1998). El derecho de los derechos humanos (la convergencia entre el derecho constitucional y el derecho internacional de los derechos humanos). En Instituto de Investigaciones Jurídicas. $V$ Congreso Iberoamericano de Derecho Constitucional. Recuperado el 15 de febrero de 2011, de http://www.bibliojuridica.org/libros/libro.htm?l=113

Bazán, V. (2007). La interacción del Derecho Internacional de los Derechos Humanos y el Derecho Interno en Argentina. (5). No 2. (pp. 137-183). Chile: Centro de Estudios Constitucionales de Chile 
Bazán, V. (2006) La relación derecho internacional de los derechos humanosderecho interno, desde un prisma iuscomparado y algunos retos que afronta el Sistema Interamericano. Red de Revistas Científicas de América Latina y el Caribe, España y Portugal Recuperado el 15 mayor de 2011, de http://redalyc.uaemex.mx/redalyc/src/inicio/ArtPdfRed. jsp?iCve $=55509818$

Birdart, Campos, G. J. (1998). La interpretación de los derechos humanos en la jurisdicción internacional y jurisdicción interna. En $V$ Congreso Iberoamericano de Derecho Constitucional. México, Instituto de Investigaciones Jurídicas. Recuperado el 15 de febrero de 2011, de http://www.bibliojuridica.org/libros/libro.htm?l=113

Carbonell, M. (2007). El neoconstitucionalismo en su laberinto. En M . Carbonell. (ed.). Teoría del neoconstitucionalismo (pp. 9-12). México: Trota.

Cançado Trindade, A. A. (2003). Las cláusulas pétreas de la protección internacional del ser humano: el acceso directo de los individuos a la justicia a nivel internacional y la intangibilidad de la jurisdicción obligatoria de los tribunales internacionales de derechos humanos. En Memoria del Seminario: El Sistema Interamericano de Protección de los Derechos Humanos en el Umbral del Siglo XXI. Tomo I (pp. 5-68). San José, C.R: Corte Interamericana de Derechos Humanos.

Cançado Trindade, A. A. (1998). Reflexiones sobre la interacción entre el Derecho Internacional y el Derecho Interno en la Protección de los Derechos Humanos. En $V$ Congreso Iberoamericano de Derecho Constitucional. México, Instituto de Investigaciones Jurídicas. Recuperado el 5 de marzo de 2011, de http://www.bibliojuridica.org/libros/libro.htm?l=113

Dulitzky, A. (1997). La aplicación de los tratados sobre derechos humanos por los tribunales locales: un estudio comparado. En Abregú, M. y Courtis, C. (Comps.). La aplicación de los tratados sobre derechos humanos por los tribunales locales (pp. 33-74). Buenos Aires, CELS.

Ferrajoli, L. (2007). Sobre los Derechos Fundamentales. En Carbonell, M. (Ed.). Teoría del neoconstitucionalismo. (pp. 71-90). México. Trota.

Gavara De Cara, J. C. (2004). Los derechos fundamentales. En J. C. Gavara De Cara. (Coord.). Constitución. Desarrollo, rasgos de identidad y valoración en el XXV aniversario (1978-2003), (pp. 15-58). Barcelona: J.M. Bosch Editor-Institut de Ciències Polítiques i Socials (ICPS). 
Hans, K. (1979). Teoría general del Estado, trad. de Luis Legaz Lacambra, México: Editorial Nacional.

Ruiz, M. C. (1997). La Ejecución de las sentencias del Tribunal Europeo de Derechos Humanos. Madrid: Tecnos.

Rodríguez-Torubes, M. J. (2000). Principios, fines y derechos fundamentales. Madrid: Dykinson.

Sánchez, Rodríguez. L. I. (1994). Los Sistemas de Protección Americano y Europeo de los Derechos Humanos: El problema de la Ejecución interna de las sentencias de las respectivas Cortes de Justicia. En R. Nieto Navia (ed.). La Corte y el Sistema Interamericano de Derechos Humanos (pp. 501- 513). Costa Rica.

Landa, C. (2007). Implementación de las decisiones del Sistema Interamericano de Derechos Humanos e el ordenamiento constitucional peruano. En Krsticevic, Viviana y Tojo Liliana (Coord.). Implementación de las decisiones del Sistema Interamericano de Derechos Humanos, Jurisprudencia, normativa y experiencias nacionales (143-160). Buenos Aires: CEJIL.

Montiel Arguello, A. (2001). Temas internacionales. Managua: Hispamer.

Meléndez, F. (2006). Instrumentos internacionales sobre derechos humanos aplicables a la administración de justicia. Estudio constitucional comparado. El Salvador.

Manili, P. (2002). La recepción del derecho internacional de los derechos humanos por el derecho constitucional iberoamericano. En R. Méndez Silva (Coord.). Derecho Internacional de los Derechos Humanos. Memoria del VII Congreso Iberoamericano de Derecho Constitucional. México: Instituto de Investigaciones Jurídicas. Recuperado el 25 de mayo de 2011, de http://www.bibliojuridica.org/libros/libro.htm?l=342

Malpica De Lamadrid, L. (2002). Revisión del Régimen Constitucional de los tratados. En Méndez Silva, R. (Coord.), Derecho Internacional de los Derechos Humanos. Memoria del VII Congreso Iberoamericano de Derecho Constitucional. México: Instituto de Investigaciones Jurídicas. Recuperado el 25 de mayo de 2011, de http://www.bibliojuridica.org/ libros/libro.htm?l=342 
Pastor Ridruejo, J. A. (2008). Palabras de Introducción. En S. Ripol Carulla \& J. I. Ugatemenda Eceizabarrena, (Coord.). España ante los Tribunales Internacionales Europeos. Cuestiones de Política Judicial (pp.309-311). Bilbao: Oñati.

Verdross, A. (1974). Derecho Internacional Público. Madrid: Aguilar.

Zalgrebelsky, G. (2007). Jueces Constitucionales. En M. Carbonell, (Ed.). Teoría del neoconstitucionalismo (pp. 91-104), México: Trota. 